\title{
Study on Combined Artificial Wetland Treatment of Urban Stream Water
}

\author{
Xiao Luo ${ }^{1, \text { a }}$, Fengping Wang ${ }^{1, \mathrm{~b}}$,Xiangyang Zheng ${ }^{1, \mathrm{c}}$,Congcong Zhao ${ }^{1, \mathrm{~d}}$,Gang \\ Hong ${ }^{2, \mathrm{e}}$,Junhua $\mathrm{Li}^{2, \mathrm{f}},{ }_{\text {, Rutai Gao }}{ }^{3, \mathrm{~g}}$, Xiangshuai Meng ${ }^{4, \mathrm{~h}},{ }_{\text {Lin }}$ Yue ${ }^{1, \mathrm{i}}$ \\ ${ }^{1}$ College of environmental science and engineering, Hebei University of Science and Technolgy, \\ Shijiazhuang 050000, PR China \\ ${ }^{2}$ Municipal environment monitoring center, Shijiazhuang 050000, PR China \\ ${ }^{3}$ Chinese Research Academy of Environmental Sciences, Beijing 100000, PR China \\ ${ }^{4}$ China nuclear power engineering co., LTD. Hebei branch, Shijiazhuang 050000, PR China \\ a59710474@qq.com, ${ }^{b}$ luoxnk@126.com, ${ }^{c}$ 1021810500@qq.com, \\ d624782253@qq.com, ,smjhh@126.com, ${ }^{\dagger} 48714653 @ q q . c o m,{ }^{9}$ grthu@126.com, \\ h443051104@qq.com, 'yuelintj@126.com
}

\begin{abstract}
Keywords: Horizontal subsurface flow artificial wetland; vertical flow artificial wetland; HRT;
\end{abstract}
Abstract. To guarantee the river water quality reaching the surface water quality standards, this paper used a small-scale experimental equipment and optimized hydraulic retention time (HRT) and optimum temperature range of the artificial wetland sewage treatment plant effluent, and the effect of advanced treatment was studied. When the HRT of horizontal subsurface flow artificial wetland is 24h and the HRT of vertical flow artificial wetland is $16 \mathrm{~h}$, in summer, the COD, Nitrogen and TP removal rate of combined artificial wetland removal rates were $85.0 \%, 75.0 \%$ and $80 \%$ respectively. COD of effluent increased when the temperature was less than $5{ }^{\circ} \mathrm{C}$ in autumn and winter, whatever horizontal subsurface flow artificial wetland, vertical flow artificial wetland or combined artificial wetland was used. Using three wetland, ammonia and TP can removed to some extent. The removal rates of ammonia were $38.2 \%, 49.8 \%$ and $69.01 \%$, respectively. TP removal rates were $61.0 \%, 66.0 \%$ and $87.0 \%$, respectively.

\section{Introduction}

At present China's urban sewage treatment plants execute the "urban sewage treatment plant pollutant emission standards" (GB18918-2002). The effluent quality should meet the GB18918-2002 1A discharge standard and then discharge into city river after the tradition treatment process of sewage ${ }^{[1]}$. But the phenomena of excessive discharge frequently occurs, coupled with the rainwater during the rainy season on the road or snowmelt runoff into the water. Research has shown that, the water quality of downstream of urban river in the United States, $82 \%$ was controlled by the surface runoff, and the major pollutants of water in the river over $50 \%$ come from urban runoff, which extremely undermines and deteriorates the non-natrual-river waters in northern cities. Therefore, it is necessary to execute advanced treatment for urban river to further reduce the concentration of nitrogen, phosphorus, refractory organic matters and other pollutants, which can make the water in the river reach Grade $V$ of national standard for surface water or Grade $C$ of landscape water standards ${ }^{[2]}$, and also let it have self-purification capacity as natural waters. The technology of artificial wetlands, based on natural wetlands and referencing the experience of waste water treatment factories, is a wastewater treatment ecosystem which artificially forms a base by using one or several materials among soil, cinder, stone, sand and other one or several medium constituting the matrix by a certain percentage. On a certain percentage and selectively implants plants. Now, the reason why the technology of artificial wetlands used as the advanced sewage treatment technology was pushed up to its climax, because it has advantages features of significant treatment effect, low construction and operation costs, easy management, but also regulates water distribution, facilitates the water balance, and with more good landscape effects ${ }^{[3]}$. The most significance is the artificial wetlands can make the non-natural-river waters become "natural waters" 
of self-purification capacity. But as the advanced treatment technology, researchers rarely combine horizontal subsurface flow artificial wetland with vertical flow artificial wetland to research treatment effect, therefore failed to adequately interpret deep sewage treatment effect of their combination and the process parameters ${ }^{[4]}$.

In this paper, a new experimental device was designed to combine horizontal subsurface flow and vertical flow artificial wetlands. In order to reveal the advanced treatment technology of artificial wetlands for river protection, a series of experiments were taken to optimize parameter ${ }^{[5]}$.

\section{Materials and methods}

Experiment sites and sewage component

The experimental device was built at the recycled water stations in Hebei University of Science and Technology and covered an area of about $9 \mathrm{~m}^{2}$. Effluent of the recycled water station was used as the influent water of this experiment. The domestic sewage was characterized by uneven flow, high water quality fluctuation, while urban river water quality has the same characteristics, so the water in the recycled water station is representative ${ }^{[6]}$. The experimental water quality conditions were shown in Tab. 1-1:

Tab. 1-1 The experiment water quality condition

\begin{tabular}{ccc}
\hline Index & $\begin{array}{c}\text { Concentration on Spring and } \\
\text { Summer }(\mathrm{mg} / \mathrm{L})\end{array}$ & $\begin{array}{c}\text { Concentration on } \\
\text { Autumn }(\mathrm{mg} / \mathrm{L})\end{array}$ \\
\hline $\begin{array}{c}\text { Chemical Oxygen } \\
\text { Demand(COD) } \\
\text { Ammonia }\end{array}$ & $35 \sim 140$ & $13 \sim 23$ \\
$\begin{array}{c}\text { Nitrogen(NH} \\
\text { Th) }\end{array}$ & $10 \sim 90$ & $6 \sim 12$ \\
Total Phosphorus (TP) & $0.26 \sim 2.5$ & $0.4 \sim 0.8$ \\
\hline
\end{tabular}

Experimental procedure and equipment

The experimental device consists of catch basins unit $(2000 \mathrm{~mm} \times 1000 \mathrm{~mm} \times 1200 \mathrm{~mm})$, horizontal subsurface flow artificial wetland unit $(3200 \mathrm{~mm} \times 1000 \mathrm{~mm} \times 850 \mathrm{~mm})$ and vertical flow artificial wetland unit $(1000 \mathrm{~mm} \times 1000 \mathrm{~mm} \times 1400 \mathrm{~mm})$. The apical height of the three units are same. The packing layer height of horizontal subsurface flow artificial wetland unit is $650 \mathrm{~mm}$. the packing layer height of vertical flow artificial wetland unit is $1200 \mathrm{~mm}$. All the height of ultrahigh are $200 \mathrm{~mm}$. Wetlands device (refer with:Fig. 1-1, 1-2, 1-3) and flow chart (refer with:Fig. 1-4) are shown as follows:

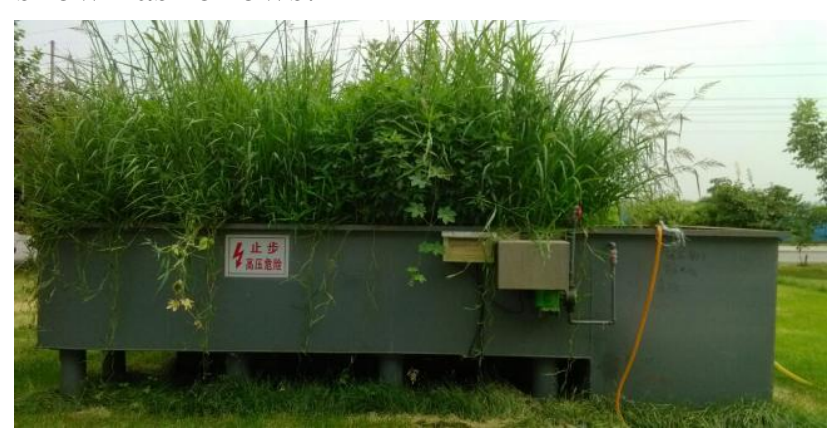

Fig.1-1 experimental device sites

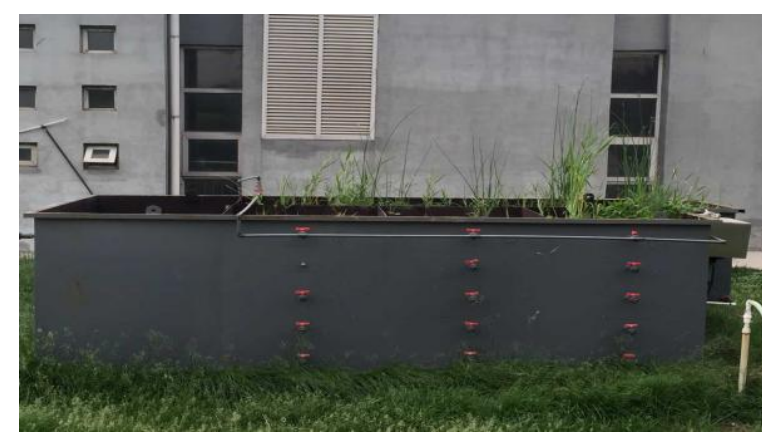

Fig.1-2 experimental device sites 


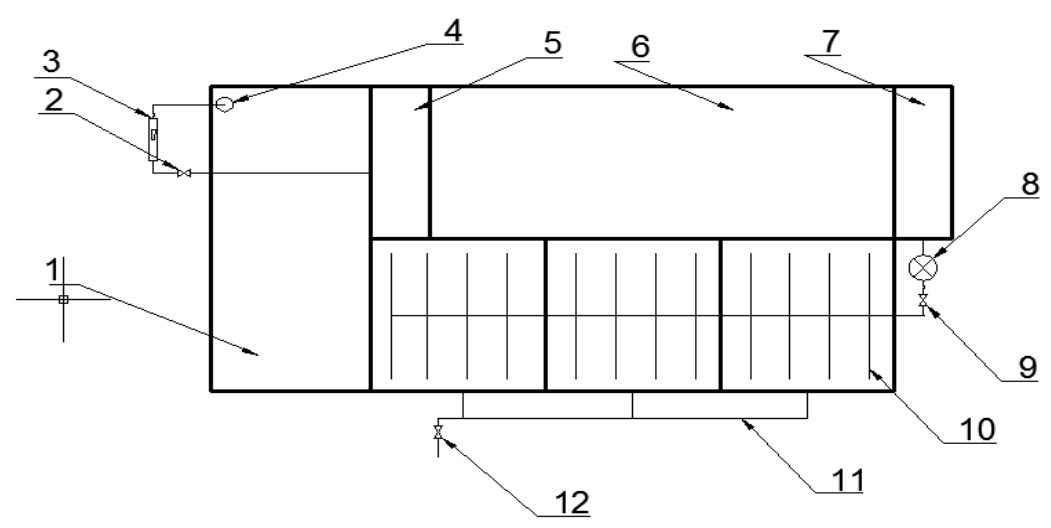

Fig. 1-3 experimental device schematic diagram
1 collecting tank
2 Valve
3 Flowmeter
4 Total intake

5 Intake of horizontal seepage 6 Horizontal subsurface flow wetland

7 Water outlet

8 Diaphragm pump 9 Valve

10 Water distributing pipe of vertical flow artificial wetland

11 Outlet pipe of vertical flow artificial wetland 12 Valve

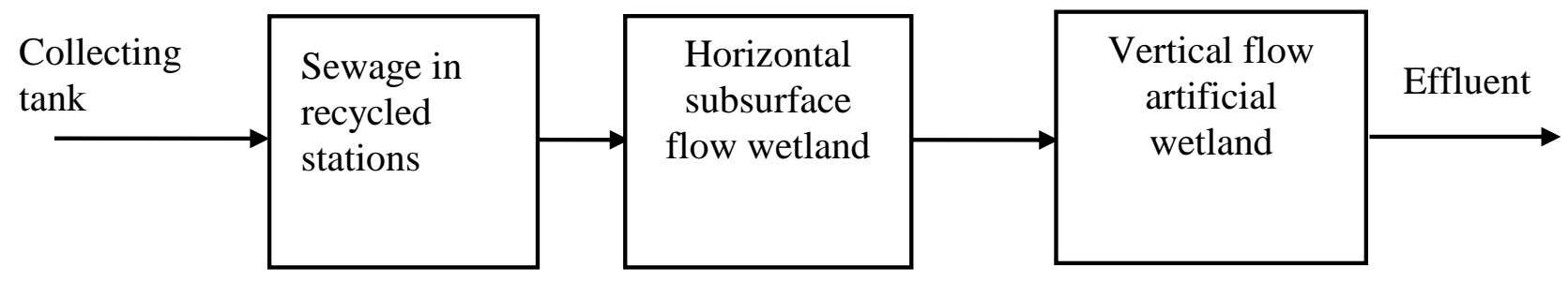

Fig.1-4 experimental flowchart

The packing layer of wetland bed is gravel, quartz sand, ceramic, zeolite and soil. The range of particle size of filler is $10 \mathrm{~mm}$ to $50 \mathrm{~mm}$. The paving pattern of horizontal subsurface flow artificial wetland is pushing flow ${ }^{[7]}$. To avoid short-circuiting caused by clogging, both the beginning and the end of the bed use large particle size gravel as filler. In order to increase the contact area between the wastewater and the filler, to improve the ability of remove contaminants, in the middle of the wetland bed, a small particle size of the zeolite was filled. The packing layer of vertical flow artificial wetland was filled hierarchically, from top to bottom followed by a mixture of soil and ceramic, ceramic, zeolite, gravel, and the particle size decrease progressively. The flow direction of vertical flow artificial wetland is over-entering and down-out ${ }^{[8]}$. The surface of the two units lays soil $^{[9]}$.

Analysis and test methods

COD, ammonia nitrogen and TP were measured. The specific method and device model are shown in Tab.1- 2

Tab. 1-2 experiment analysis method and equipment

\begin{tabular}{llll}
\hline Index & Analysis Methods & $\begin{array}{l}\text { Analytical } \\
\text { Instrument }\end{array}$ & Production Type \\
\hline $\mathrm{COD}$ & Potassium Dichromate Method & microwave dissolver & $\begin{array}{l}\text { AC-10,Tsingtao } \\
\text { Shandong }\end{array}$ \\
& & V-Vis & 754PC, Shanghai \\
$\mathrm{NH}_{3}-\mathrm{N}$ & nessler's reagents & spectrophotometer & \\
& spectrophotometer & V-Vis & 754PC, Shanghai \\
$\mathrm{TP}$ & $\begin{array}{l}\text { Ammonium molybdate } \\
\text { spectrophotometric method }\end{array}$ & spectrophotometer & \\
\hline
\end{tabular}


system operation

Numbers of reeds and scirpus tabernaemontani were planted in artificial wetlands experimental device (refer with: Fig.1-2). The device was started in march, 2014, which was domesticated by using domestic sewage in water-recycling station with continuous water input. Startup is completed when effluent quality gets stability ${ }^{[10]}$.

It took one month to start the process. The experimental period covers 8 months from April, 2014 to November, 2014. The different HRT was investigated among the most flourishing period from June to September (refer with: Fig.1-1).

\section{Results and discussion}

From Apri1 1 to August 30, 2014, the hydraulic retention time (HRT) of horizontal subsurface flow wetland (HSFCW) and vertical flow artificial wetland (VSFCW) is controlled separately as follow:

We have controlled the hydraulic retention time (HRT) of horizontal subsurface flow wetland (HSFCW) and vertical flow artificial wetland (VSFCW) separately:(1)HRT (HSFCW) $_{\text {equals } 24 h, \text { HRT }}$ (VSFCW) equals 16h; (2)HRT (HSFCW) $_{\text {e }}$ equals 34h, HRT (VSFCW) equals $31 \mathrm{~h}$; (3)HRT (HSFCW) $_{\text {( }}$ equals $12 \mathrm{~h}$, HRT (VSFCW) equals 12h; Influent and effluent water samples were analyzed once a day during the experiment. The effects of treatment under different HRT have some variation regulation, and eventually get stable. Finally representative data was taken respectively.

Effect of HRT on COD removal efficiency

As shown in Fig. 2-1, when HRT (HSFCW) equals 24h, HRT (VSFCW) equals $16 \mathrm{~h}$, the removal rate of COD increased with time prolonged. In the first 19 days, the COD removal rate reached its maximum, COD removal rate was $85 \%$. When the time was further extended, COD removal efficiency became stabilized. The total COD removal rate of combined artificial wetland varied from $85 \%$ to $90 \%$. Data obtained from analyses of influent and effluent water samples showed that total COD average removal rate of combined artificial wetland was $55.5 \%$, while the removal rate of horizontal subsurface flow artificial wetland was $36.7 \%$ and the removal rate of vertical flow wetland was $29.7 \%$.

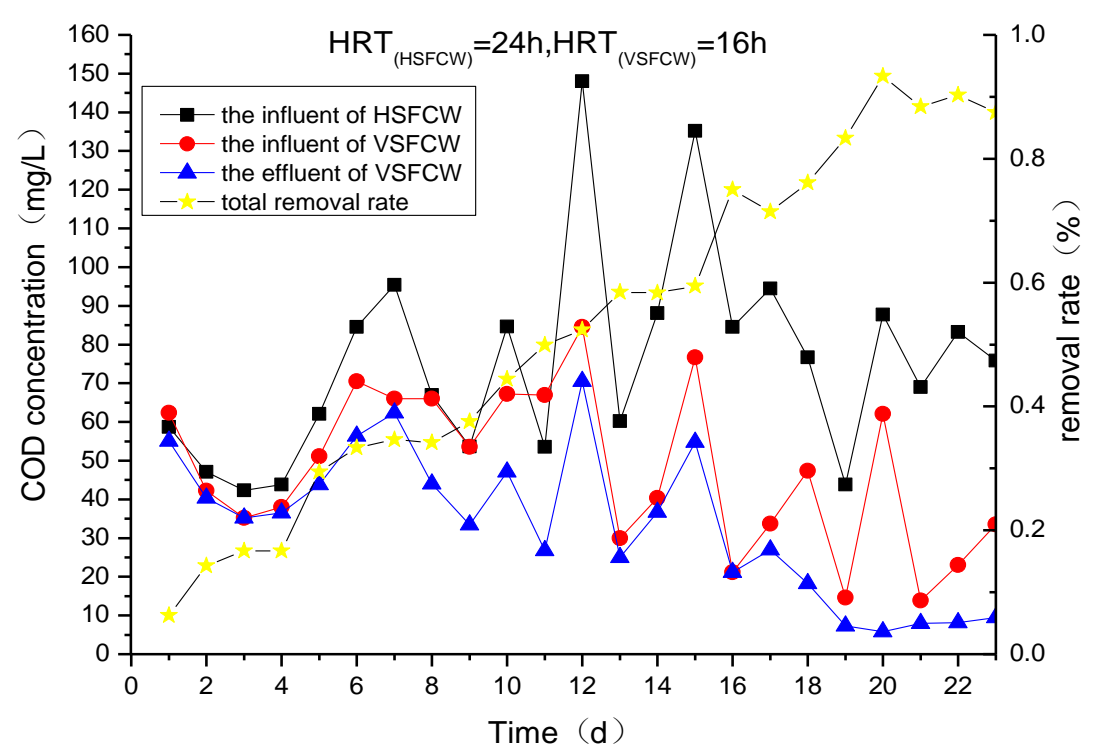

Fig. $2-1$ HRT $(\mathrm{HSFCW})=24 \mathrm{~h}, \mathrm{HRT}(\mathrm{VSFCW})=16 \mathrm{~h}$, The removal of COD

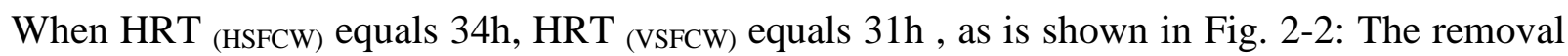
rate of COD increased with time prolonged. In the first 19 days, the COD removal rate reached it's maximum, which was $75 \%$. When the time is further extended, COD removal rate became stabilized. The removal rate of COD varied from $75 \%$ to $80 \%$. The total COD average removal rate 
of combined artificial wetland was $53.3 \%$, while the removal rate of horizontal subsurface flow artificial wetland was $41.4 \%$ and the removal rate of vertical flow wetland was $20.3 \%$.

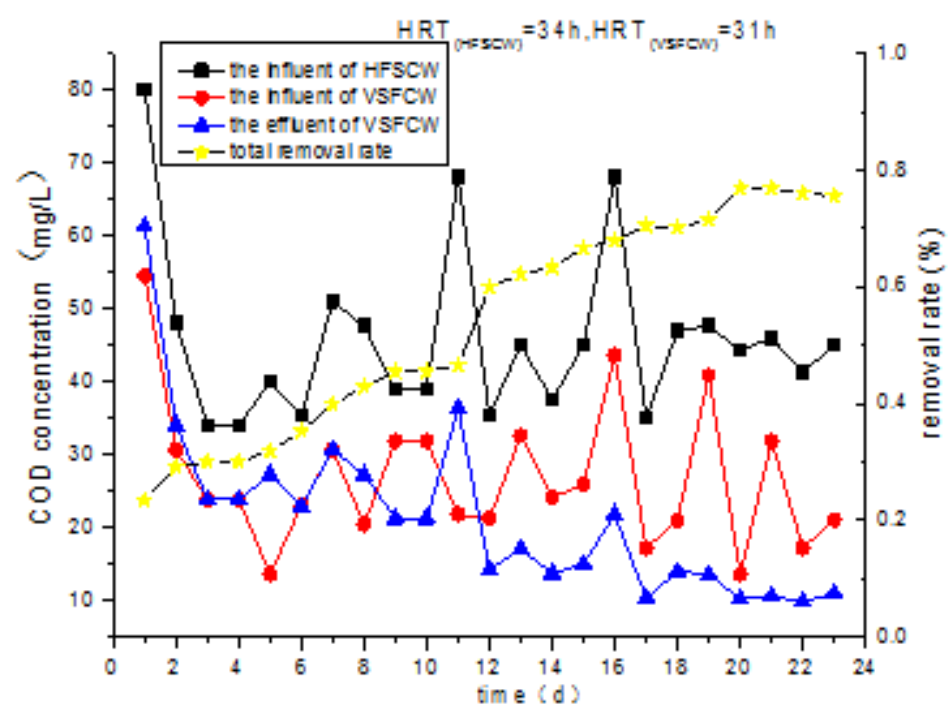

Fig. $2-2$ HRT $($ HSFCW $)=34 \mathrm{~h}$, HRT $(\mathrm{VSFCW})=31 \mathrm{~h}$, The removal of COD

Fig. 2-3 shows: when HRT (HSFCW) $_{\text {equals12h, HRT (VSFCW) }}$ equals $12 \mathrm{~h}$, the removal rate of COD increased with time prolonged. In the first 13 days, the COD removal rate reached it's maximum, which was $45 \%$. When the time was further extended, COD removal rate became stabilized. The total removal rate of COD was varing from $40 \%$ to $45 \%$. Treated by horizontal subsurface flow, the COD concentration in the sewage decreased significantly. However, the COD concentration increased rather than decreased after treated by the vertical flow unit reaction ${ }^{[11]}$.

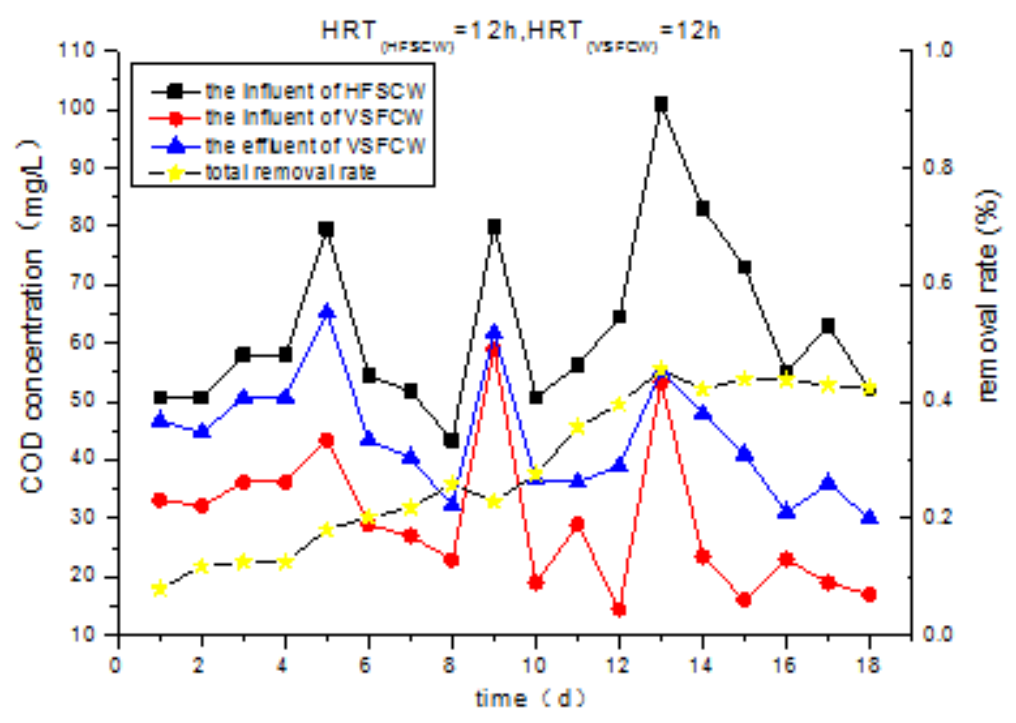

Fig. $2-3 \mathrm{HRT}$ (HSFCW $)=12 \mathrm{~h}, \mathrm{HRT}_{\text {(VSFCW })}=12 \mathrm{~h}$, The removal of $\mathrm{COD}$

To sum up , firstly, the changes of HRT always results in worse treatment-effect in short term, but it will reach a new maximum soon and remains a stable state. Stabilization time of the best removal rate, under the three kinds of HRT, was basically 18 days to 19 days. Analysis results indicated that the artificial wetland can resist the loading fluctuation to some extent. The possible reason may be that microorganism accumulated continuously on the filler up to the most and organic matter in sewage is effectively degraded state until removal effect is fair good ${ }^{[12]}$. When the HRT was changed, before reaching a stable, the original microorganism passed a short-time of sludge acclimation. Secondly, the horizontal subsurface flow artificial wetlands for COD removal efficiency are better than vertical flow wetlands. The possible reason may be that large amount 
microorganism, in the unit of horizontal subsurface flow artificial wetlands, possess the characteristics of large in quantity, rapid metabolism and adsorption.

Effect of HRT on TP removal efficiency

Fig. 2-4 shows: when $\mathrm{HRT}_{(\mathrm{HSFCW})}$ equals $34 \mathrm{~h}$, HRT (VSFCW) $_{\text {equals }} 31 \mathrm{~h}$, the removal rate of TP increased with time prolonged. In the first 18 days, the TP removal rate reached it's maximum, which was $65 \%$. When the time was further extended, TP removal rate became stabilized. The total TP average removal rate of combined artificial wetland was $40.4 \%$, while the removal rate of horizontal subsurface flow artificial wetland was $16.35 \%$, and the removal rate of vertical flow wetland was $28.8 \%$.

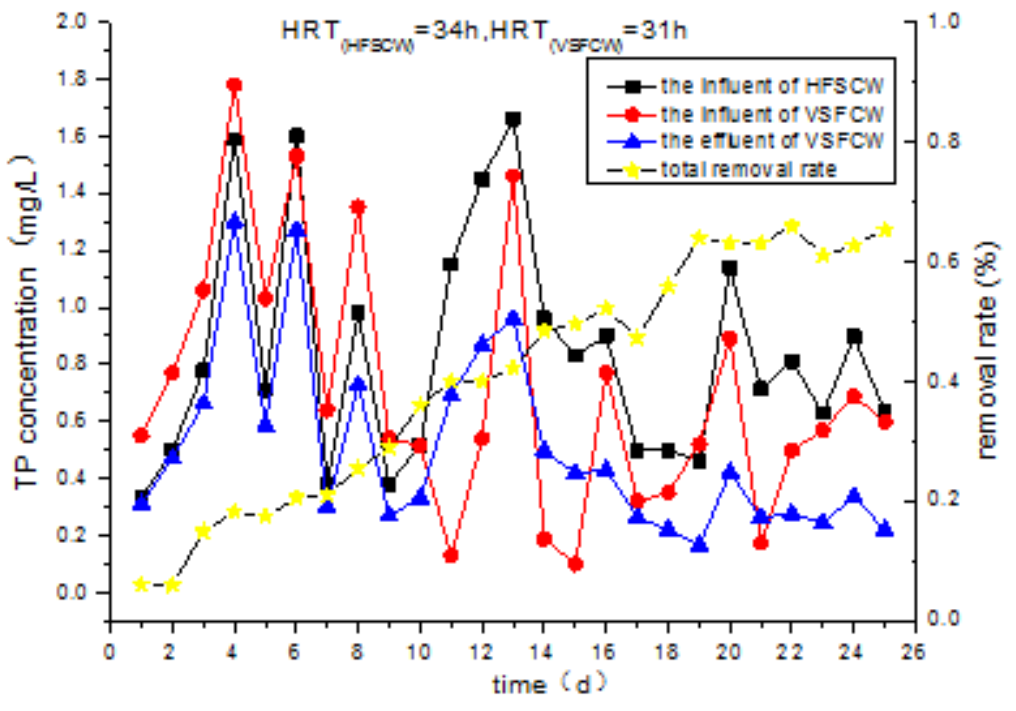

Fig. 2-4 HRT $(\mathrm{HSFCW})=34 \mathrm{~h}, \quad \mathrm{HRT}(\mathrm{VSFCW})=31 \mathrm{~h}$, The removal of TP

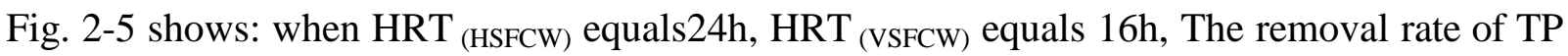
increased with time prolonged. In the first 13 days, the TP content vary from $1.8 \mathrm{mg} / \mathrm{L} 2.5 \mathrm{mg} / \mathrm{L}$ down to $1.2 \mathrm{mg} / \mathrm{L} \sim 1.7 \mathrm{mg} / \mathrm{L}$ abruptly, and the removal rate rose to $68 \%$ from $45 \%$, and it basically reached it's maximum $70 \%$. When the time is further extended, TP removal rate became stabilized. The total TP average removal rate of combined artificial wetland was $45.5 \%$, while the removal rate of horizontal subsurface flow artificial wetland was $23.5 \%$, the removal rate of vertical flow wetland was $28.7 \%$.

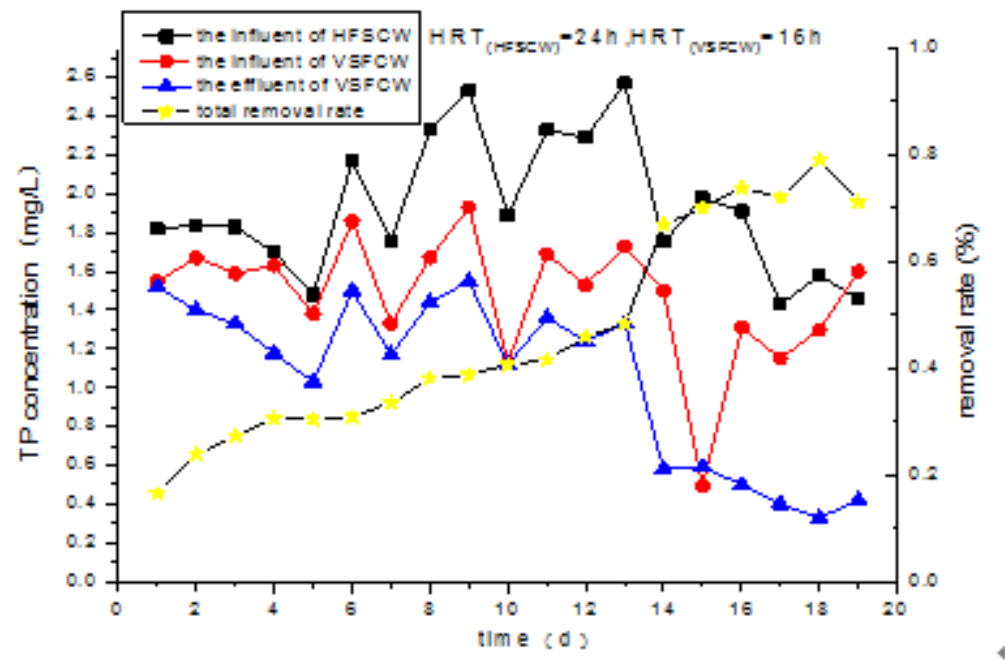

Fig. 2-5 HRT $($ HSFCW $)=24 h$, HRT $(V S F C W)=16 h$, The removal of TP 
Fig. 2-6 shows: when HRT ${ }_{(\mathrm{HSFCW})}$ equals12h, HRT ${ }_{\text {(VSFCW) }}$ equals $12 \mathrm{~h}$. In the first 10 days, the TP removal rate became stabilized and the figure was $61 \%$. Data obtained from results shows: the total TP average removal rate of combined artificial wetland was $47.8 \%$, while the removal rate of horizontal subsurface flow artificial wetland was $18.7 \%$, the removal rate of vertical flow wetland was $35.8 \%$.

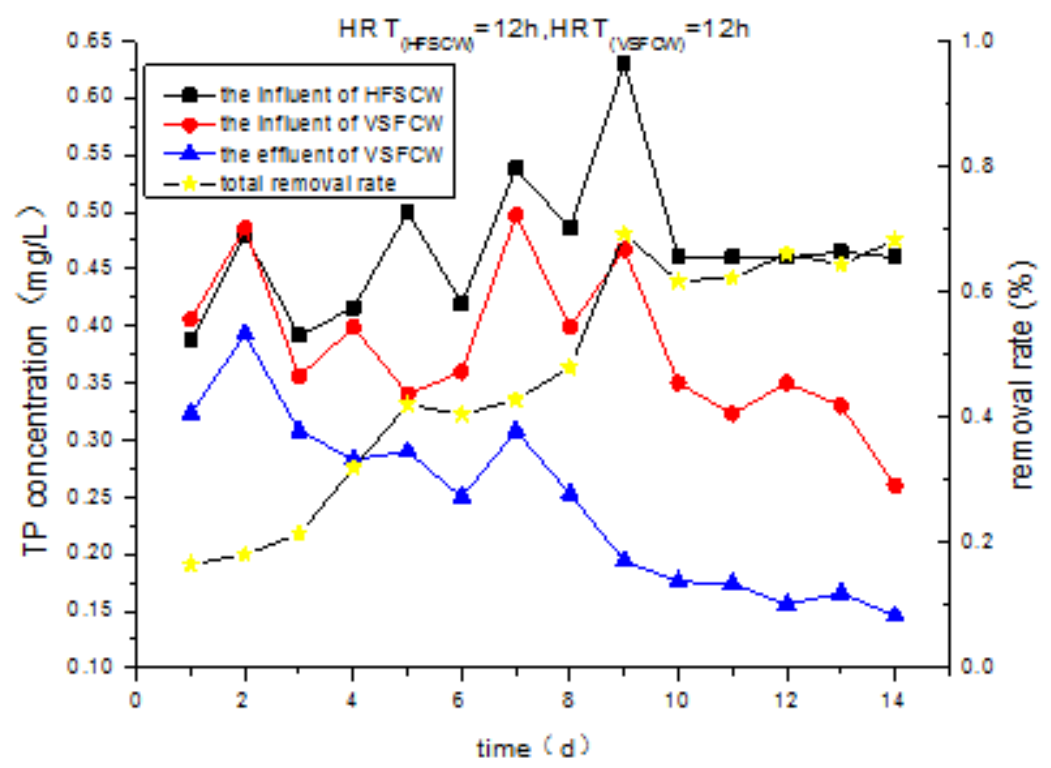

Fig. $2-6 \mathrm{HRT}_{(\mathrm{HSFCW})}=12 \mathrm{~h}, \mathrm{HRT}(\mathrm{VSFCW})=12 \mathrm{~h}$, The removal of TP

In summary, when the HRT was changed, the removal laws of TP and COD are similar in the sewage, the stability time of the removal rate under 3 types of HRT is the 10th day to 18th day. Secondly, the efficiency of vertical flow artificial wetland for TP removal is superior to horizontal subsurface flow artificial wetland unit. That may be due to vertical flow unit has formed a significant aerobic-anaerobic zone.

Effect of HRT on the ammonia nitrogen $\left(\mathrm{NH}_{3}-\mathrm{N}\right)$ removal efficiency

Fig. 2-7 shows: when HRT ${ }_{(\mathrm{HSFCW})}$ equals34h, $\mathrm{HRT}_{(\mathrm{VSFCW})}$ equals $31 \mathrm{~h}$. In 19 th day, the total $\mathrm{NH}_{3}-\mathrm{N}$ average removal rate of combined artificial wetland became stabilized, the maximum was $85 \%$. The average removal rate of horizontal subsurface flow artificial wetland unit was $20 \%$, the removal rate of vertical flow wetland was $50.5 \%$.

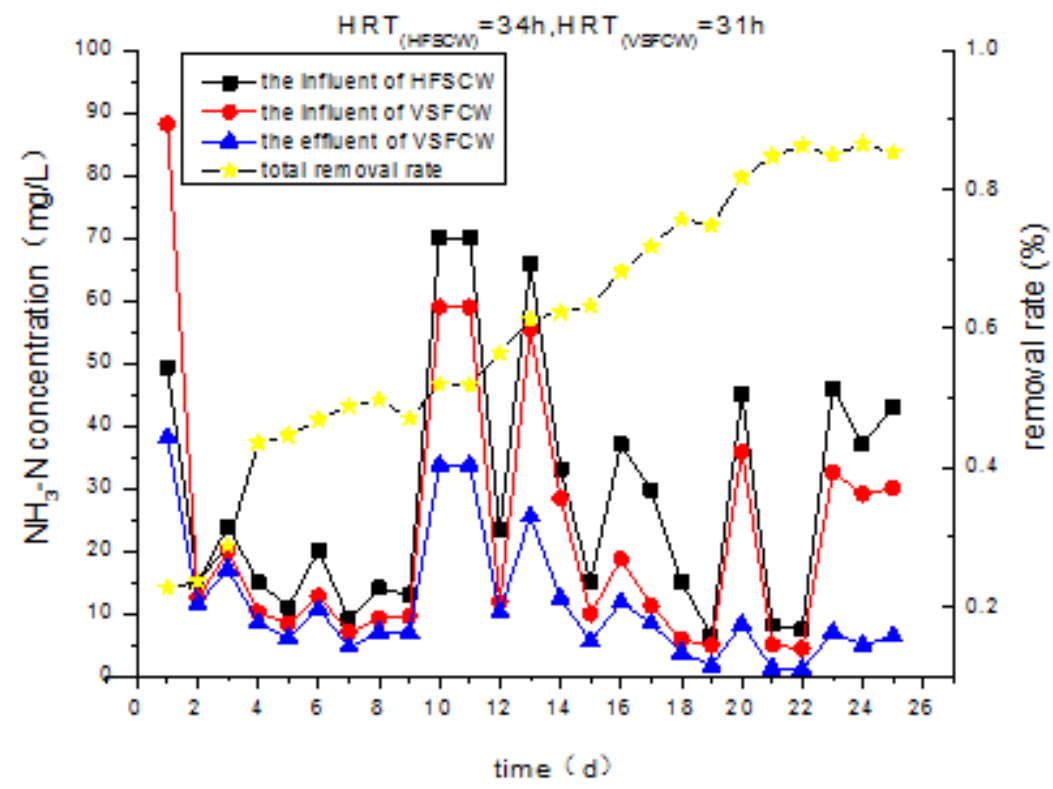

Fig. $2-7$ HRT $($ HSFCW $)=34 \mathrm{~h}, \quad$ HRT $(\mathrm{VSFCW})=31 \mathrm{~h}$, The removal of Ammonia 
Fig. 2-8 shows: when $\mathrm{HRT}_{(\mathrm{HSFCW})}$ equals24h, $\mathrm{HRT}_{(\mathrm{VSFCW})}$ equals 16h,in 19th day, the total $\mathrm{NH}_{3}-\mathrm{N}$ average removal rate of combined artificial wetland became stabilized and peaked, the maximum was $80 \%$. The removal rate of horizontal subsurface flow artificial wetland unit was $26.63 \%$, the removal rate of vertical flow wetland unit was $32 \%$.

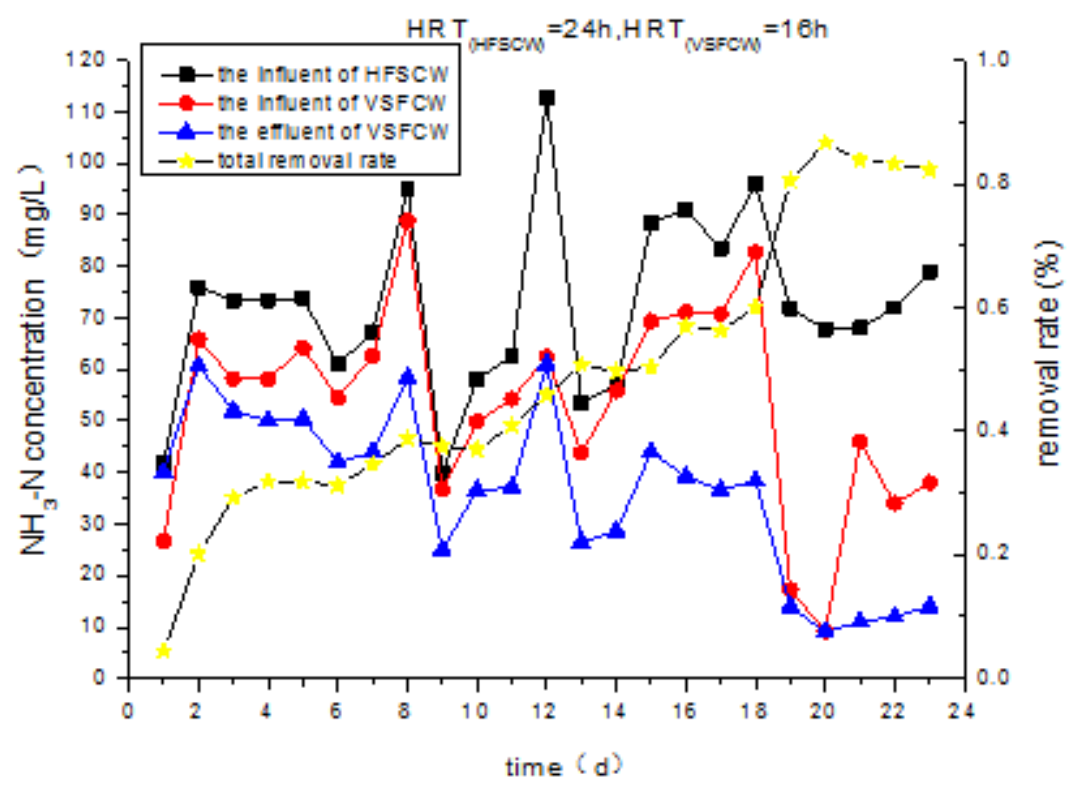

Fig. $2-8 \mathrm{HRT}(\mathrm{HSFCW})=24 \mathrm{~h}, \quad \mathrm{HRT}(\mathrm{VSFCW})=16 \mathrm{~h}$, The removal of Ammonia Nitrogen

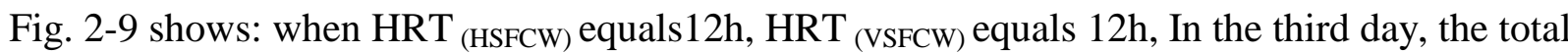
$\mathrm{NH}_{3}-\mathrm{N}$ average removal rate of combined artificial wetland became stabilized and peaked, and the maximum was $45 \% \sim 55 \%$. The removal rate of horizontal subsurface flow artificial wetland unit was $20.2 \%$, the removal efficiency of vertical flow wetland unit was $33 \%$.

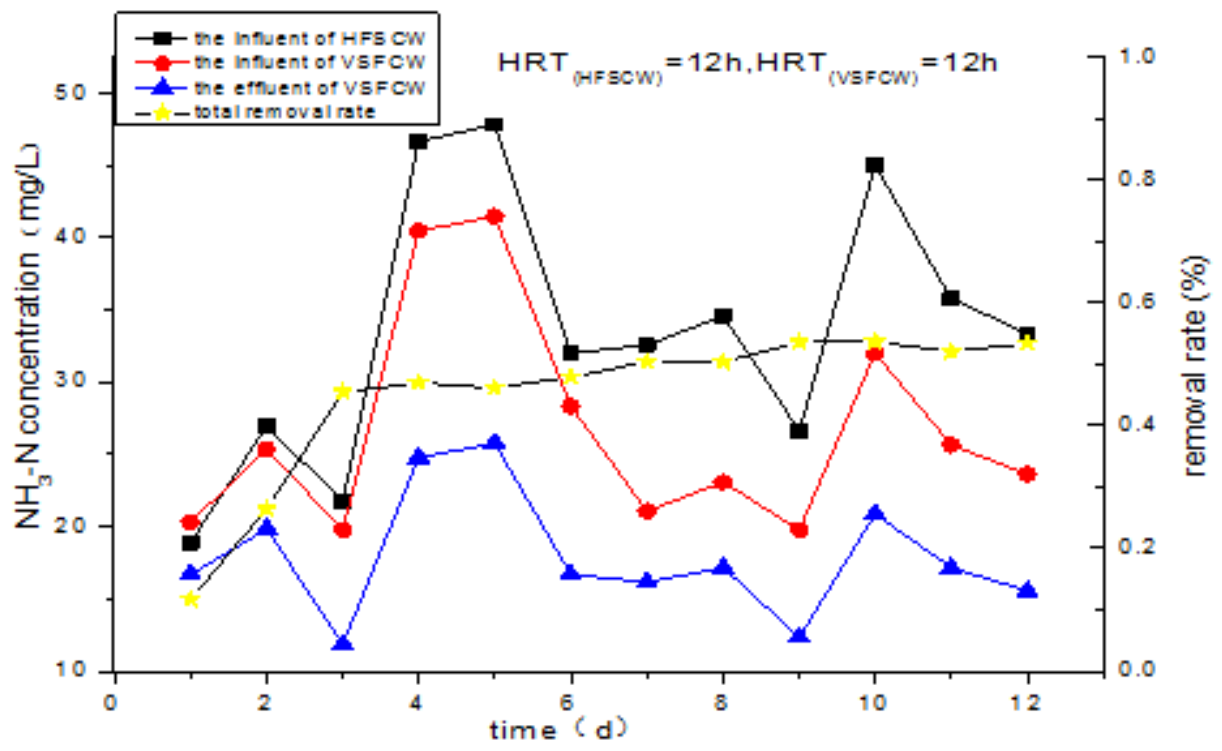

Fig. 2-9 HRT $($ HSFCW $)=12 \mathrm{~h}, \mathrm{HRT}_{(\mathrm{VSFCW})}=12 \mathrm{~h}$, The removal of Ammonia Nitrogen

In summary, statistical evaluation of the data obtained for removal rates related to COD,TP and $\mathrm{NH}_{3}-\mathrm{N}$ showed that when HRT (HSFCW) equals $24 \mathrm{~h}, \mathrm{HRT}$ (VSFCW) equals $16 \mathrm{~h}$, the removal rates of COD,TP are the highest in the combined artificial wetland. When HRT (HSFCW) equals $34 \mathrm{~h}$, HRT (VSFCW) equals $31 \mathrm{~h}$, the removal rates of $\mathrm{NH}_{3}-\mathrm{N}$ is the highest of $85 \%$ in the combined artificial wetland. But when HRT ( $\mathrm{HSFCW}$ ) equals $24 \mathrm{~h}, \mathrm{HRT}$ ( $\mathrm{VSFCW}$ ) equals $16 \mathrm{~h}$, the removal rate of $\mathrm{NH}_{3}-\mathrm{N}$ is 
$80 \%$,there are little difference between the two cases. Comprehensively consideration. when HRT (HSFCW) equals $24 \mathrm{~h}, \mathrm{HRT}$ (VSFCW) equals 16h,the treatment of the combined artificial wetland is under the condition of optimum efficiency. The removal rate was higher than the individual pollutant removal rate of the vertical flow artificial wetland or horizontal subsurface flow artificial wetland in PR China National Environmental Protection Standards "wetland sewage treatment project technical specifications" HJ 2005-2010. Probably because the HRT is too short, the microorganisms hardly ever fully absorb nutrients in sewage; When HRT is too long, the endogenous respiration intensified and microorganisms died. In addition, the impact factors of the removal rate not only related to HRT, but also with the water quality ${ }^{[13]}$.

Analysis and Research about wetland treatment effect in November

The temperature is gradually reduced in October and November, 2014. The load of influent and effluent are low in recycled water stations in the two months, and the effluent water was used as experimental influent.

Influent and effluent water samples of the experiment were analyzed in every 2 days during the experiment. Then the valid data were compared and analyzed: the removal effect had no significant changes in October compared with previous data. With the decreasing of temperatures, some change had happened in November. The diurnal temperature deceased from $20{ }^{\circ} \mathrm{C} \sim 5{ }^{\circ} \mathrm{C}$ in November 1,2014 to $6{ }^{\circ} \mathrm{C} \sim 1{ }^{\circ} \mathrm{C}$ in November 21,2014 gradually.

Shown by Figure 2-10: this process has increased COD value rather than decreased, Probably because the higher diurnal temperature variation was negative to the removal of COD in North ${ }^{[13]}$.

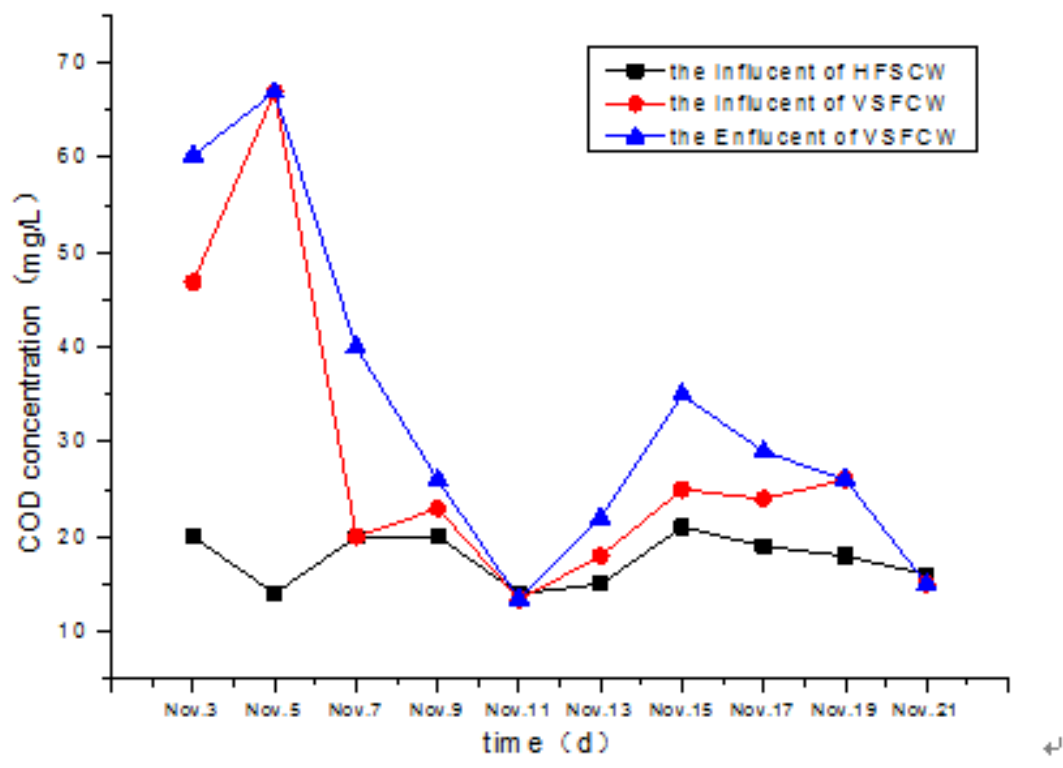

Fig. 2-10 In and out of the water COD concentration and it's removal rate

But the removal effect of wetlands for $\mathrm{NH}_{3}-\mathrm{N}$, TP remained relatively significant. Fig. 2-11, Fig. 2-12 shows that when the $\mathrm{NH}_{3}-\mathrm{N}$, TP of influent meets the first grade A standards $(15 \mathrm{mg} / \mathrm{L}, 1 \mathrm{mg} / \mathrm{L})$, The final effluent, namely the total water quality of vertical flow artificial wetland units total water, was stability controlled less than $2.0 \mathrm{mg} / \mathrm{L}, 0.15 \mathrm{mg} / \mathrm{L}$ respectively. The $\mathrm{NH}_{3}-\mathrm{N}$ removal rate of horizontal subsurface flow artificial wetland unit and vertical flow artificial wetland unit were $38.2 \%, 49.8 \%$ respectively, the total removal rate was $69.01 \%$. The TP removal rate of horizontal subsurface flow artificial wetland unit and vertical flow artificial wetland unit were $61 \%, 66 \%$ respectively, the total removal rate was $87 \%$. Therefore, it can be seen: vertical flow unit for $\mathrm{NH}_{3}-\mathrm{N}$, TP treatment efficiency is better than horizontal subsurface flow unit. Obvious aerobic zone, anaerobic zone, aerobic zone might be formed sequentially in vertical flow unit; whereas, in horizontal subsurface flow, aerobic zone and anaerobic zone were sure to exist, but the denitrification or P release were not thorough in final stage ${ }^{[14]}$. 


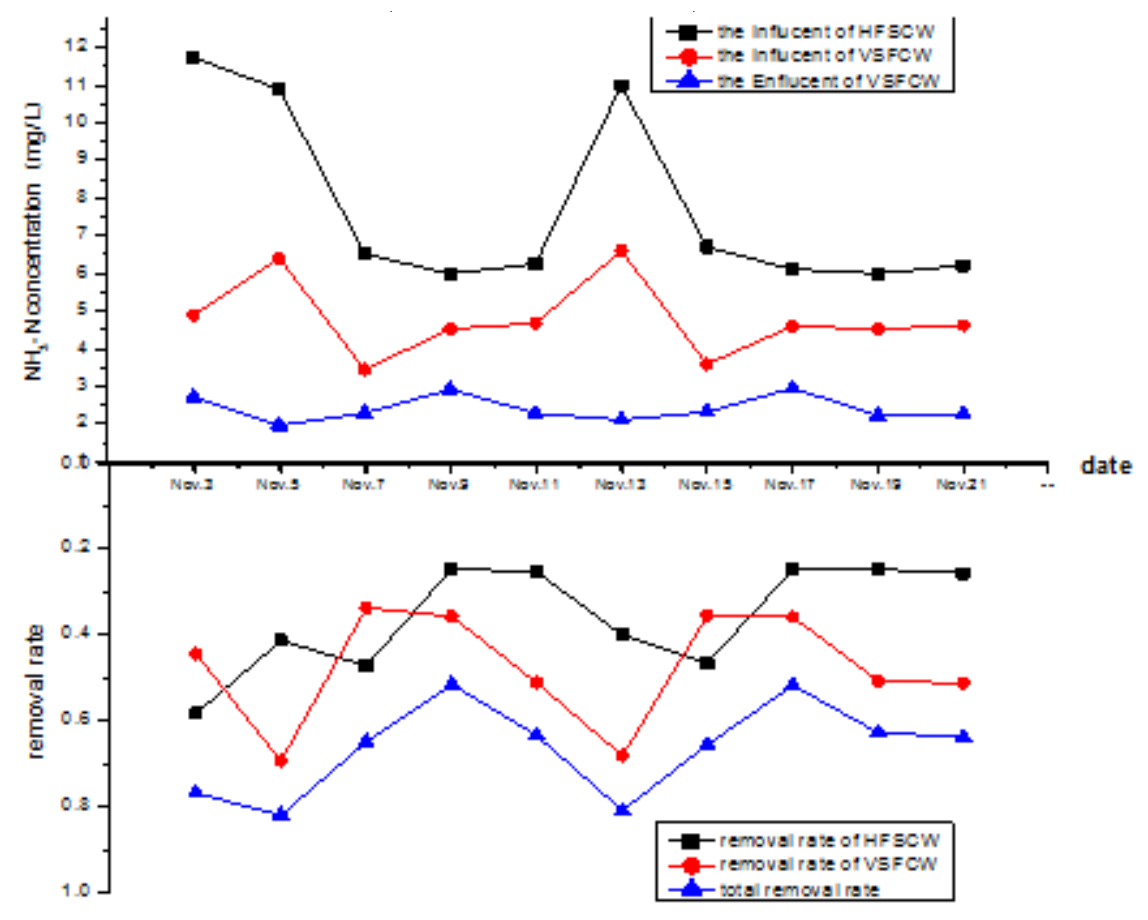

Fig. 2-11 In and out of the water Ammonia Nitrogen concentration and it's removal rate

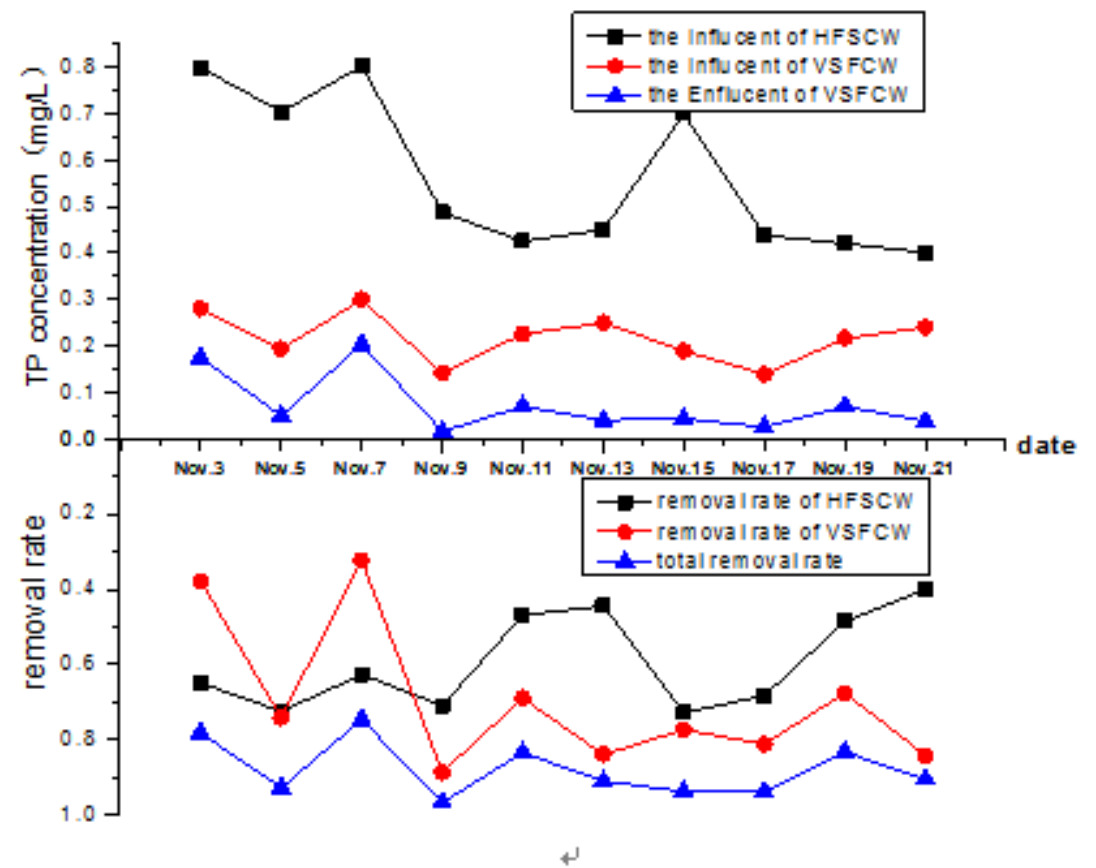

Fig.2-12 In and out of the water TP concentration and it's removal rate

\section{Conclusions}

(1) The Nitrogen and TP removal effect of vertical flow artificial wetland is better than the horizontal subsurface flow artificial wetland, while its removal efficiency of COD is lower than the horizontal subsurface flow artificial wetland.

(2) When changing the HRT, original microorganisms need a period to be domesticated. That is, the combined process posses a certain capability of resistance to impact load. When HRT (HSFCW) was $24 \mathrm{~h}$ and HRT (VSFCW) was $16 \mathrm{~h}$, combined artificial wetland has a better effect on the removal 
of $\mathrm{COD}, \mathrm{NH}_{3}-\mathrm{N}$, TP. total removal rates of $\mathrm{COD}, \mathrm{NH}_{3}-\mathrm{N}, \mathrm{TP}$ are $85.0 \%, 75.0 \%$ and $80 \%$, respectively.

(3) Influent quality may have some impact on the removal rates of pollutants ${ }^{[15]}$.

(4) $\mathrm{The} \mathrm{NH}_{3}-\mathrm{N}$ total removal rate of combined artificial wetland are higher than the individual pollutant removal rate of the vertical flow artificial wetland or horizontal subsurface flow artificial wetland in PR China National Environmental Protection Standards "wetland sewage treatment project technical specifications" HJ 2005-2010.

(5) It is not conducive for the combined process to the removal of COD owing to the low temperature in the north. While the removal rates for $\mathrm{NH}_{3}-\mathrm{N}$, TP were not influenced when the diurnal temperature is $6^{\circ} \mathrm{C} \sim 1^{\circ} \mathrm{C}$.

\section{References}

[1]Wang Ni, Li Jing-wen and Xie Jian-Cang, in: Dynamic research of urban river water environment capacity.in Environmental Engineering, (2014).

[2]Mou Hong-Li,in: Upgrading reconstruction to study the technology of Heze Zhong-Ke-Cheng sewge treatment plant, edtied by Qingdao Technological University,Qingdao,(2014).in press. [3]Hao Xia-Guang,in: Study on sewage treatment plant process of the city of OUBEI, edtied by Qingdao Technological University,Qingdao,(2013).in Press.

[4]Gan Shu-Ying, Wang Zheng, Yang Qing, Wu Yi-Ping and Dai Xue-Min, in: Research of technologies for biological nitrogen and phosphorus removal in traditional activated sludge WWTP, volume 34 of Progress in Water \& Wastewater Engineering, (2008).

[5]Guo Fu-Rong,in: The study of denitrifying and dephosphorization of urban sewage of integrated denitrification biological aerated filter, edtied by Taiyuan University of Technology,

Taiyuan,(2011),in Press.

[6]Cui Fang, in: Study on the artificial wetland treatment for urban lakes, edtied by Xi'an University of technology, Xi'an, (2008), in Press.

[7]Guan Ce, Yu Da-Wei, Zheng Xiang and Wei Yuan-Song, in: Removing nitrogen and phosphoros of effluent from wastewater treatment plants by artificial wetlands in china, volume 31 of Progress in Jourual of Agro-Envirment Science, chapter, 12,(2012).

[8]Zeng Jing-qi, in:Study on Enhanced Artificial wetland for Treatment of Domestic Sewage in Northern Area, edtied by Beijing Jiaotong University, Beijing, (2014) ,in Press.

[9]Caselles-Osorio A and Garcia J, in: Impact of different feeding strategies and plant presence on the performance of shallow horizontal subsurface-flow artificial wetlands, volume 378 of Progress in Sci Total Environ, chapter, 10,(2007).

[10]Zhang Sheng, He Feng, Cheng Shui-ping, Liang Wei and Wu Zhen-bin, in:On phosphorus removal efficiency in eight kinds of different combination systems of wetland, volume 17 of Progress in Resources and Environment in the Yangtze Basin, chapter, 2,(2008).

[11] Liang Wei, Wu Zhen-bin, Cheng Shui-ping and et al, in: Roles of substrate microorganisms and urease activities in wastewater purification in a artificial wetland system, volume 21 of Progress in Ecological Engineering,(2003).

[12] Sun G, Zhao Y and Allen S, in: Enhanced removal of organic matter and ammoniacal- nitrogen in a column experiment of tidal flow artificial wetland system, volume 115 of Progress in Journal of Biotechnology, chapter, 2,(2005).

[13]Xu Li, Ge Da-bing and Xie Xiao-kui, in: Impact of Hydraulic Retention Time on Wetland Running, volume 30 of Progress in Chinese Agricultural Science Bulletin, chapter, 31,(2014). [14]Gao Xiang, Huang Jin-hui, Zhang Zhong-guang, Zhou Xu-shen, in: Test research on tail water of Artificial wetland sewage treatment plants, volume 12 of Progress in south-to-north water transfer \& water conservancy science and technology, chapter, 1, (2013). 
[15]J.L. Lin, Y.T. Tu, P.C. Chiang, S.H. Chen and C.M. Kao, in: Using aerated gravel-packed contact bed and artificial wetland system for polluted river water purification: A case study in Taiwan, volume 525 of Progress in Journal of Hydrology,(2015). 